\title{
Copanlisib in the Treatment of Relapsed Follicular Lymphoma: Utility and Experience from the Clinic
}

This article was published in the following Dove Press journal:

Cancer Management and Research

\author{
Ayushi F Chauhan' \\ Bruce D Cheson (D) ${ }^{2}$ \\ 'Department of Hematology and \\ Oncology, Lombardi Comprehensive \\ Cancer Center, MedStar Georgetown \\ University Hospital, Washington DC, \\ USA; ${ }^{2}$ Scientific Advisory Board, \\ Lymphoma Research Foundation, \\ Washington, DC, USA
}

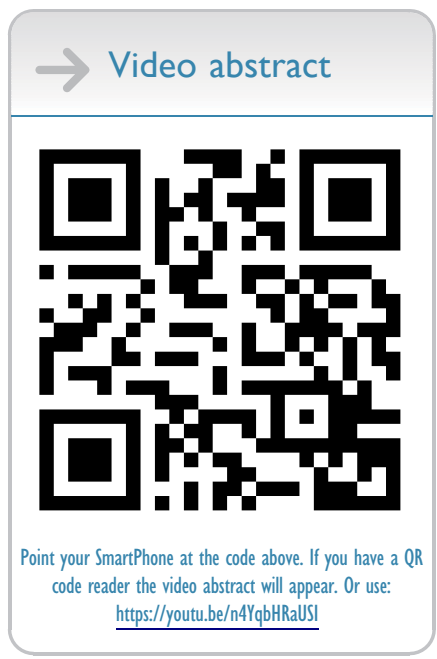

Correspondence: Ayushi F Chauhan Email ayushi.chauhan@gunet.georgetown. edu

\begin{abstract}
The phosphatidylinositol-3-kinase (PI3K) pathway is ubiquitous to multiple cellular processes and is intricately implicated in lymphomagenesis. The development of PI3K inhibitors has broadened treatment options for relapsed and/or refractory follicular lymphoma (FL) and currently three PI3K inhibitors have been approved in the third-line setting for FL, including idelalisib (oral), duvelisib (oral), and copanlisib (intravenous), with other agents under investigation. In this review, we discuss the clinical advance of copanlisib through preclinical to Phase III trials, its unique cellular targets and side effect profile that have poised it as a safer and equally efficacious option when compared to the oldergeneration oral PI3Kis, and its utility to the clinician as part of the therapeutic armamentarium for relapsed and/or refractory FL.
\end{abstract}

Keywords: copanlisib, follicular lymphoma, PI3K inhibitors

\section{Introduction}

Follicular lymphoma (FL) is an indolent non-Hodgkin lymphoma (NHL) derived from germinal center B-cells. Significant improvements in outcomes have been attained in the rituximab era such that most patients will experience a prolonged remission after frontline therapy. However, FL is still considered an incurable disease in most patients and exhibits a relapsing, remitting course. Thus, the majority of patients will be exposed to multiple lines of therapy during their lifetime. Therapies used to treat progressive disease have mostly utilized antiCD20 monoclonal antibodies (class I and II), with or without cytotoxic chemotherapy, or with lenalidomide. ${ }^{1}$ Also, survival outcomes progressively decline with subsequent lines of therapy. ${ }^{2}$ The unmet need for additional tolerable and effective treatment options in subsequent relapses has led to the development of targeted agents, amongst them phosphatidylinositol-3-kinase (PI3K) pathway inhibitors.

\section{Background and Rationale}

FL can be considered to possess three pathobiological targets: the cell surface, the intracellular compartment, and the tumor microenvironment. The PI3K pathway mediates signaling in each of these domains and has prognostic implications. PI3Ks belong to a conserved family of lipid kinases, activated by growth factor receptor tyrosine kinases which, in turn, lead to the recruitment and stimulation of a wide range of downstream, including the serine-threonine protein kinase Akt and mechanistic target of rapamycin (mTOR). Phosphatase and tensin homolog (PTEN) is a notable negative regulator of this pathway. PI3K pathway is at the 
epicenter of an extraordinarily broad range of cellular regulatory processes, including cell growth and proliferation, metabolism, migration, and secretion and upregulation of PI3K signaling has been considered a hallmark of cancer. $^{3-5}$

Human cells express 3 classes of PI3K enzymes, of which class I are implicated in lymphoid malignancies and pertinent to the current review. Class I is subdivided in class IA and IB based on modes of regulation. Class IA are heterodimers, containing one catalytic subunit p110 $\alpha$, $\mathrm{p} 110 \beta$, or $\mathrm{p} 110 \delta$, that associates with any of the regulatory subunits $\mathrm{p} 85 \alpha, \mathrm{p} 55 \alpha, \mathrm{p} 50 \alpha, \mathrm{p} 85 \beta$, or $\mathrm{p} 55 \gamma$ forming PI3K $\alpha$, $\mathrm{PI} 3 \mathrm{~K} \beta$, and $\mathrm{PI} 3 \mathrm{~K} \delta$, respectively. Class $\mathrm{IB}$ is also a heterodimer, consisting of the catalytic subunit $\mathrm{p} 110 \gamma$ and the regulatory subunit $\mathrm{p} 101$ or $\mathrm{p} 84$ forming $\mathrm{PI} 3 \mathrm{~K} \gamma$. $\mathrm{p} 110 \alpha$ and $\mathrm{p} 110 \beta$ are ubiquitously expressed in various tissues while $\mathrm{p} 110 \gamma$ and $\mathrm{p} 110 \delta$ are mainly expressed in leukocytes. Sixty percent of PI3K activity in B-cells is accounted for by the $\mathrm{p} 110 \delta$ isoform and this, hence, has been the focus of drug development in lymphomas. ${ }^{6}$

At the B-cell surface, the B-cell receptor (BCR) is a ubiquitously expressed protein with BCR signaling regulating multiple B-cell biological functions, such as growth, proliferation, differentiation, and survival. BCR also plays a role in follicular lymphomagenesis, both through auto-reactivity ${ }^{7}$ and antigen-independent signaling via interaction of mannosyl residues on surface-expressed BCR with lectins expressed on stromal cells in the tumor microenvironment. ${ }^{8-10}$ Intracellular signal transduction of BCRs is almost invariably dependent on PI3K signaling and in mature $\mathrm{B}$ cells, PI3K activity interweaves with B-cell receptor (BCR) signaling, regulated in both a $\mathrm{B}$-cell receptor $(\mathrm{BCR})$ dependent and $\mathrm{BCR}$-independent manner. ${ }^{6}$ This interdependence underscores the critical role of PI3K pathway in FL lymphomagenesis.

Intracellularly, PI3K activation, at least in part, enhances the apoptosis-resistance provided by Bcl-2 overexpression, which is central to FL pathogenesis. ${ }^{11}$ FL cells demonstrate elevated basal levels of spleen tyrosine kinase (Syk), a downstream molecule in the PI3K pathway, and studies have shown a key role of the Syk/mTOR axis in FL survival. ${ }^{12}$ Ablation of $\mathrm{p} 110 \delta$ in mice blocks pro-B cell differentiation with decreased numbers of circulating, mature B cells, suggesting an indispensable role in B-cell follicular maturation and survival. Class I PI3K aberrancy has been frequently implicated in many forms of B-cell malignancies, such as chronic lymphocytic leukemia (CLL), mantle cell lymphoma (MCL), and diffuse large
B-cell lymphoma (DLBCL). A subset of FL patients shows activation of PI3K, demonstrated by Akt phosphorylation, a downstream kinase of PI3Ks.

The tumor microenvironment is key to lymphomagenesis. There is extensive, bi-directional cross-talk between FL and stromal cells. Stromal cells promote FL cell survival through recruitment of cell adhesion molecules, cytokines, and chemokines. ${ }^{13} \mathrm{PI} 3 \mathrm{~K} \delta$ blockade in mice models has been shown to abrogate production of cytokines such as IL-6 and IL-10 ${ }^{14}$ and NK-cell chemokine production. ${ }^{15}$ Idelalisib (formerly CAL-101), a PI3 $\delta$ inhibitor, disrupted $\mathrm{T}$ and NK-cell cytokine production in CLL preclinical models supporting the pathogenetic role of this pathway. ${ }^{16}$ PI3K $\delta$ inhibition also interrupts CXCR12 mediated chemotaxis. ${ }^{17}$ Overall, PI3K inhibition disrupts supportive lymphoma-tumor microenvironment interactions contributing to anti-tumor activity.

p110 $\delta$ expression also appears to have a prognostic role in FL. Dong et al examined expression of p110 $\delta$ and CD9 (a tetraspanin protein involved in diverse cellular processes such as motility, adhesion, and differentiation) on 76 FL tumor tissues and 15 normal tissues with immunohistochemistry (IHC). FL patients expressed high levels of $\mathrm{p} 110 \delta$ and low levels of CD9. The upregulation of PIK3CD and downregulation of CD9 was associated with higher Ann Arbor stages and a shorter progressionfree survival (PFS). These results suggested that gain of p110 $\delta$ increases the recurrence risk of FL and could be a predictor of tumor progression and FL aggressiveness. ${ }^{18}$ Taken together, there is a sound biological rationale for targeting PI3K pathway in FL (Figure 1).

\section{Pi3k Inhibitor Development in Lymphoma}

The biggest challenge in PI3K inhibitor (PI3Ki) development has been achieving the balance between sufficient depth of target inhibition in tumor tissue and dose-limiting toxicities. Initially, pan-specific PI3K/mTOR and pan$\mathrm{PI} 3 \mathrm{~K}$ inhibitors were developed in an attempt to augment therapeutic efficacy. However, trials in solid tumors demonstrated unacceptable toxicities. ${ }^{5}$ Isoform-selective and isoform-sparing PI3K inhibitors, by circumventing intrinsic toxicity of pan-PI3K inhibition and allowing exploration of combination therapies, thus, became the new focus for research.

Given the prominent role played by $\mathrm{p} 110 \delta$ in lymphoid malignancies, isoform-specific $\mathrm{PI} 3 \mathrm{~K} \delta$ inhibitors were 


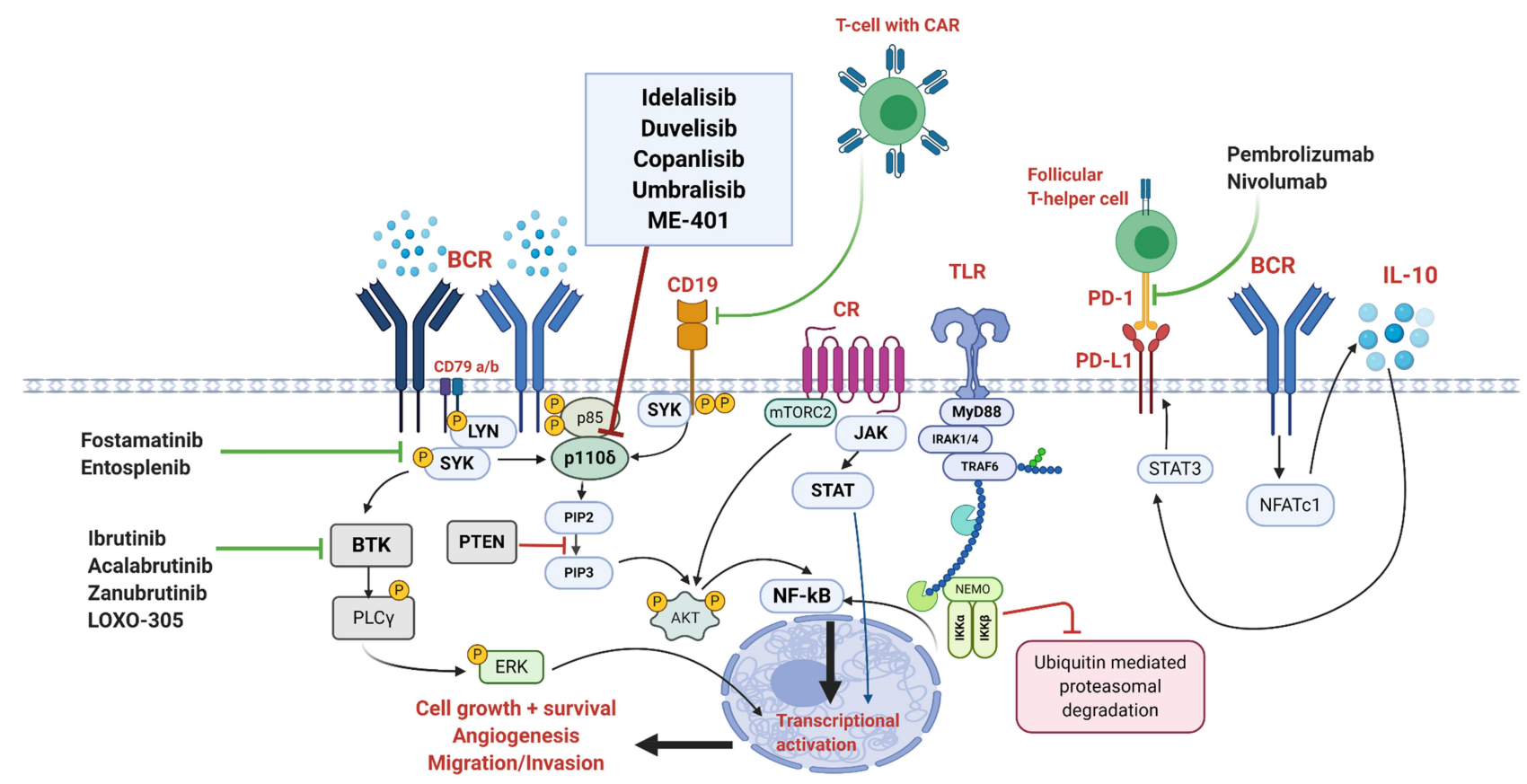

Figure I The PI3K pathway in the context of BCR signaling along with various targets. The BCR pathway is activated through antigen binding followed by recruitment and stimulation of LYN/SYK, resulting in phosphorylation of tyrosine residues on adapter proteins on the BCR as well as CDI9. This enables the docking of PI3K regulator subunit to the $\mathrm{BCR}$ and CDI9 and activation of the PI3K pathway. Activated PI3K phosphorylates PIP2 into PIP3 which stimulates PH domain signaling molecules including Akt. LYN/SYK also activate the BTK pathway which instigates PLC $\gamma 2$ activation. The result of these processes is intranuclear transcriptional activation promoting cell survival. PTEN is a prominent negative regulator of this pathway. Also shown is the role of follicular T-helper cells and the PD-I/PDL-I pathway. Created with BioRender.com.

Abbreviations: Akt, a serine/threonine-specific protein kinase; BCR, B-cell receptor; BTK, Bruton tyrosine kinase; CAR, chimeric-antigen receptor; CR, chemokine receptor; ERK, extracellular-signal-regulated kinase (major signaling cassette of mitogen-activated kinase pathway); IKK- $\alpha / \beta$, inhibitor of NF- $K B$; IRAK I/4, interleukin-I receptor-associated kinase 4; JAK, Janus tyrosine kinase; LYN, Lck/yes novel tyrosine kinase; mTOR, mechanistic target of rapamycin; MYD88, myeloid differentiation primary response 88; NEMO, NF-KB essential modulator; NFATcI, nuclear factor of activated T-cells cytoplasmic I; NF-KB, nuclear factor kappa-B; PD-I, programmed death-I; PDL-I, programmed death-I ligand; PH, pleckstrin homology; PIP2, phosphatidylinositol 4,5-bisphosphate; PI3K, phosphatidylinositol-3 kinase; PIP3, phosphatidylinositol 3,4,5-triphosphate; PLC 2 , phospholipase C-gamma PTEN, phosphatase and tensin homolog; STAT, signal transducer and activator of transcription; SYK, spleen tyrosine kinase; TLR, toll-like receptor; TRAF6, tumor necrosis factor receptor-associated factor 6 .

investigated. Idelalisib (selective PI3K- $\delta$ inhibitor) and duvelisib (PI3K $\delta / \gamma$ dual isoform-specific inhibitor) have been approved for FL, relapsed/refractory (R/R) after 2 prior lines of therapy. ${ }^{1,19}$ Unfortunately, the initial enthusiasm concerning these agents was dampened by a high incidence of gastrointestinal and immune-mediated toxicities. $^{20,21}$

Copanlisib (BAY 80-6946; Bayer Pharma AG, Berlin, Germany) is an intravenous, potent, highly selective, panclass I PI3K inhibitor with preferential activity against the $\mathrm{p} 110 \alpha$ and $\mathrm{p} 110 \delta$ isoforms, compared with the $\mathrm{p} 110 \beta$ and p110 $\gamma$ isoforms. ${ }^{22}$ Copanlisib is indicated in the US for the treatment of patients with relapsed follicular lymphoma (FL) who have received at least two prior systemic therapies. $^{23}$

\section{Preclinical Studies}

The in vivo antitumor efficacy (determined as a function of tumor growth inhibition) of copanlisib was studied in athymic nude rats or nude mice using xenograft models of human tumors. ${ }^{22}$ Following a single intravenous dose of $6.0 \mathrm{~L} / \mathrm{kg}$, copanlisib potently inhibited the catalytic activity of all class I PI3K isoforms with highest inhibition of $\alpha$ and $\gamma$ isoforms (IC50 values for $\alpha, \beta, \gamma$, and $\delta$ isoforms were $0.5,3.7,6.4$, and $0.7 \mathrm{nmol} / \mathrm{L}$, respectively).

This study showed potent antiproliferative activity of copanlisib against a diverse panel of human tumor cell lines, many of which exhibited constitutively activated PI3K signaling. ${ }^{22}$ Several breast cancer, endometrial cancer, and hematologic tumor cell lines were particularly sensitive at IC50 values less than $10 \mathrm{nmol} / \mathrm{L}$. Cell proliferation inhibition was thought to correlate with the strong activity of copanlisib against the $\alpha$ and $\delta$ isoforms.

\section{Pharmacokinetics}

Copanlisib exhibited a very large volume of distribution (Vss $=32 \mathrm{~L} / \mathrm{kg}$ ) resulting in high tumor penetrance as well as a high plasma clearance $(3.95 \mathrm{~L} / \mathrm{kg} /$ hour $(\mathrm{h}))$ and long half-life $(6.0 \mathrm{~h}) .^{22}$ At $48 \mathrm{~h}$, copanlisib levels in tumors were 100 -fold higher than in plasma. There was a strong 
pharmacokinetic (PK)-pharmacodynamic relationship with tumor Copanlisib levels correlating well with inhibition of tumor AKT phosphorylation. Levels of pAKT-Ser473 in tumors showed more than $90 \%$ inhibition at $24 \mathrm{~h}$ after intravenous dosing and remained suppressed for 48 to 72 h. pAKT reduction was observed as early as $1 \mathrm{~h}$ after intravenous dosing. Elimination of copanlisib and its metabolites is predominantly through hepatic metabolism and biliary excretion with more than $90 \%$ of in vitro metabolism mediated by cytochrome P450 (CYP) 3A4 and less than $1 \%$ by CYP $1 \mathrm{~A} 1 .^{24}$

Aforementioned exposure and other PK parameters remained similar following multiple administrations (every second day $\times 5$ ), signifying lack of compound accumulation of compound or metabolic process alterations. An alternative dosing schedule of intravenous copanlisib twice a day once weekly for also showed equivalent antitumor activity.

Subsequently, Paul et al performed PI3K isoform and PTEN expression analysis with primary tumors from 45 FL and 45 DLBCL patients. ${ }^{25}$ High PI3K $\delta$ expression was noted in $87 \%$ of FL patients. Only $18 \%$ of FL patients demonstrated both PI3K $\delta$ and PI3K $\alpha$ overexpression however PI3K $\alpha$ overexpression correlated with a late disease stage $(\mathrm{p}=0.06)$ and a high Follicular Lymphoma International Prognostic Index (FLIPI) risk score $(\mathrm{p}=$ 0.01 ) indicating $\mathrm{PI} 3 \mathrm{~K} \alpha$ contribution to disease progression and a prognostic role. Hence, dual inhibition of the $\alpha$ and $\delta$ isoforms could be especially pertinent in FL with poor prognostic features, which, in turn, is more likely to exhibit refractoriness to front-line therapies, paving the way for study of copanlisib in the Phase I setting.

\section{Phase I Trials}

Patnaik et al conducted the first-in-human study of copanlisib in patients with advanced solid tumors and NHL. ${ }^{26}$ Fifty-seven patients were treated with copanlisib on days 1,8 , and 15 of a 28 -day cycle. Preclinical studies showed a lack of drug accumulation despite multiple doses potentially translating to lower rates of cumulative toxicities. This, in conjunction with the observation that pAKT phosphorylation remained suppressed $48-72 \mathrm{~h}$ post copanlisib administration and equivalent efficacy of the twice a day weekly schedule with every other day schedule, established the clinical rationale for weekly, intermittent dosing. The dose escalation cohort included 17 solid-tumor patients and 9 NHL patients out of which 6 had FL. The maximal tolerated dose (MTD) was $0.8 \mathrm{mg} / \mathrm{kg}$ due to multiple grade 3-4 dose-limiting toxicities (DLTs) experienced by one patient with metastatic colon carcinoma. These DLTs included grade 3-4 transaminitis, grade 4 hyperglycemia with lactic acidosis, elevated anion gap and increased serum ketones, and grade 3 left ventricular systolic dysfunction, starting on the day of the first copanlisib infusion, resolving after drug discontinuation.

Patients with NHL received a median of 10 treatment cycles (range, 1-49 which was higher than that in the solid-tumor expansion cohort (median of 2 treatment cycles (range, 1-14)). Of note, the longest duration of study treatment was received by $2 \mathrm{FL}$ patients, one of whom was treated for $>4$ years before disease progression and another who remained on treatment for $>3$ years (at time of data cut off). The NHL patients were heavily pretreated, suggesting a better tolerability profile of copanlisib in NHL, especially FL.

The aforementioned study also had a distinct cohort for patients with Type 2 diabetes mellitus (T2DM) who were treated at a lower dose level of $0.4 \mathrm{mg} / \mathrm{kg}$. Most common $(\geq 20 \%)$ drug-related adverse events (AEs) of any grade were hyperglycemia (63\%), nausea (37\%), and hypertension $(21 \%)$. However, both blood glucose and blood pressure elevations were relatively transient returning to baseline within $24-48 \mathrm{~h}^{26,27}$

Copanlisib exhibited a distinct gastrointestinal (GI) toxicity profile compared to what was previously seen with the orally administered PI3K inhibitors. For the orally administered PI3K inhibitors idelalisib and duvelisib, the reported incidence of all-grade and grade $\geq 3$ diarrhea ranged from $32 \%$ to $92 \%$ and $9 \%$ to $20 \%$, respectively, while the reported incidence of grade $\geq 3$ elevations in aminotransferases was up to $25 \%$, and serious GI toxicity, such as colitis, was reported in $4 \%$ of patients. In contrast, with copanlisib administration, nausea was the most common drug-related GI toxicity (37\%; all events grade $\leq 2)$ and diarrhea was less common (all-grades: $16 \%$; grade $\geq 3$ : $2 \%)$. Elevated aminotransferases were primarily an incidental laboratory toxicity finding and mostly grade 1 . GI toxicities were noted to be class effects of PI3K inhibitors, however, their reduced incidence and severity associated with copanlisib was thought to suggest a beneficial role for intravenous administration which would bypass high gut concentrations and first-pass metabolism due to oral agents. Gedatolisib (PKI-587), another intravenous dual PI3K/mTOR inhibitor with pan-PI3K inhibitory activity, similarly demonstrated a low incidence of diarrhea and 
transaminitis supporting the advantage of bypassing the gut. $^{28}$

Another smaller Phase 1 study evaluated 10 Japanese patients with advanced or refractory solid tumors. ${ }^{27}$ Copanlisib was administered at $0.8 \mathrm{mg} / \mathrm{kg}$. The toxicity profile was similar to Patnaik et al albeit with a slightly higher incidence of all-grade hypertension (70\% vs $21 \%$ ) and hyperglycemia ( $80 \%$ vs $63 \%$ ), respectively.

Overall, Copanlisib was noted to be safe with a significantly lower GI toxicity rate as compared to the commercially available oral PI3K inhibitors.

\section{Phase II Trials}

CHRONOS-1 was a pivotal phase II trial of copanlisib in relapsed/refractory aggressive and indolent lymphomas. In Part A, 33 patients with indolent lymphoma and 51 with aggressive lymphoma received copanlisib at a dose of $0.8 \mathrm{mg} / \mathrm{kg}$ intravenously over a 1 -h infusion on days 1 , 8 , and 15 of a 28 -day cycle. ${ }^{29} \mathrm{FL}$ comprised $48.5 \%$ of patients. Most patients (78.6\%) had received prior rituximab and 54.8\% were rituximab-refractory. Median duration of treatment was 23 and 8 weeks in the indolent and aggressive cohorts, respectively. Of 80 patients evaluable for efficacy, the objective response rate (ORR) was $43.7 \%$ in the indolent cohort and $27.1 \%$ in the aggressive cohort with a median progression-free survival (PFS) of 9.7 and 2.3 months and median duration of response (DOR) of 12.8 and 5.5 months, respectively. The ORR of $40 \%$ in FL patients was slightly lower than reported with idelalisib $(48-57 \%)$ in a similar indolent lymphoma population. ${ }^{30,31}$ The AE profile was consistent with that noted in phase I studies, with the most common being hyperglycemia $(57.1 \%$; grade $\geq 3,23.8 \%)$ and hypertension (54.8\%; grade $\geq 3,40.5 \%$ ). Diarrhea was more frequent than noted in phase 1 trials with an incidence of $40.5 \%$ (grade $\geq 3$, $4.8 \%$ ). However, as in phase 1 studies, both hyperglycemia and hypertension were transient, with blood pressure peaking 1 to $2 \mathrm{~h}$ after the start of infusion, and plasma glucose levels peaking 5 to $8 \mathrm{~h}$ after the start of infusion, followed by a decline to baseline levels. Neither of these required treatment discontinuations. Neutropenia also occurred in $28.6 \%$ of patients (grade $4,11.9 \%$ ). Copanlisib dosage and administration schedule was as established in phase 1 studies $(0.8 \mathrm{mg} / \mathrm{kg}$ on days 1,8 , and 15 of a 28 -day cycle).

The authors also conducted tumor gene expression and mutation analyses that confirmed low prevalence of PIK3CA mutations and frequent upregulation of PI3K pathway gene expression in lymphomas. Copanlisib exhibited increased antitumor activity in cases with activated $\mathrm{PI} 3 \mathrm{~K} / \mathrm{BCR}$ signaling and this, taken together with low expression of unfavorable tumor microenvironment genes, was a proof-of-principle for its mechanism of action. Based on these results, the efficacy of copanlisib was studied in an extension cohort of patients with indolent lymphoma (Part B).

CHRONOS-1 part B included relapsed/refractory indolent lymphoma patients and the and safety of copanlisib (60 mg IV dose), based on promising results noted in part A. ${ }^{32}$ The study accrued 142 patients relapsed/refractory after at least 2 prior lines of therapy; 104 patients had FL (73\%) and $23(16.2 \%)$ had MZL. The ORR was 58.7\% vs $70 \%$ with complete remissions (CR) in $14.4 \%$ vs $9 \%$, respectively, in FL versus marginal zone lymphoma (MZL). Median DOR was 22.6 months, and the median PFS was 11.2 months. High expression of PI3K/BCR pathway genes was found in $75 \%$ of evaluated patients with an ORR, including 6 of 8 with a CR, and in 25 of 33 (76\%) evaluable patients with FL with an objective response and in 5 of 6 with a CR. 9 of 17 FL (53\%) patients with low PI3K/BCR gene expression did not respond to copanlisib (stable (SD) or progressive disease (PD) or tumors that were not evaluable for gene expression profiling) while only 12 of 37 FL (32.4\%) patients with high $\mathrm{PI} 3 \mathrm{~K} / \mathrm{BCR}$ expression were non-responders. Upregulation of PI3K pathway genes, hence, appears to portend an improved response to copanlisib. Most common AEs were transient hyperglycemia (41\%) and transient hypertension (24\%).

Of the FL subset, $62 \%$ were refractory to their last regimen. ${ }^{30}$ Patients had received a median of 3 prior lines of treatment. In addition to an ORR of $58.7 \%$, $44.2 \%$ patients had a partial response (PR). The median DOR was 12.2 months in patients with CR or PR. Most patients were able to remain on treatment with median duration of treatment being 22 weeks and $32 \%$ patients remaining on treatment at the initial data cut off of June 2016. Most common AEs were (all grade/grade 3+): diarrhea $(34 \% / 5 \%)$, neutropenia $(30 \% / 24 \%)$, fatigue $(30 \% / 2 \%)$, and fever $(25 \% / 4 \%)$. Hyperglycemia $(50 \% /$ $41 \%)$ and hypertension (30\%/24\%) were transient. All toxicities were manageable, with a low incidence of severe AEs associated with other PI3K inhibitors, especially hepatic enzymopathy, opportunistic infections, and colitis.

A 2-year updated analysis of CHRONOS-1 supported continued efficacy and safety benefit for copanlisib in relapsed/refractory indolent lymphomas. ${ }^{33}$ The efficacy 
analysis showed an improved ORR of $60.6 \%$ with 24 CRs and 62 PRs as compared to $21 \mathrm{CRs}$ and $40 \mathrm{PRs}$ at the time of primary analysis. There were 3 new CRs since primary analysis and 4 partial responses that became CR endpoints of median DOR, PFS, and overall survival (OS) were 14.1 months (median follow-up, 16.1 months), 12.5 months (median follow-up, 14.0 months), and 42.6 months (median follow-up, 31.5 months), respectively. Median safety followup was 6.7 months and $26 \%$ of patients received treatment for more than 1 year. Common treatment-emergent adverse events (TEAEs) (all grade/grade 3/grade 4) were transient hyperglycemia $(50.0 \% / 33.1 \% / 7.0 \%)$, diarrhea $(35.2 \% / 8.5 \%$ / $0 \%)$, transient hypertension $(29.6 \% / 23.9 \% / 0 \%)$, and neutropenia $(28.9 \% / 9.2 \% / 14.8 \%)$. These serious AEs were largely unchanged, with no new cases of pneumonitis $(4.2 \%)$, diarrhea $(2.8 \%)$, or grade 5 events. Unlike orally administered PI3K inhibitors, there were no black box warnings or chronic adverse events. These long-term data are highly encouraging with improving responses without new safety concerns.

\section{Phase III Trials}

Ongoing phase III trials using copanlisib in indolent lymphomas include CHRONOS-2 (NCT02369016), CHRONOS-3 (NCT02367040) and CHRONOS-4 (NCT02626455) (Table 1 ), all of which are currently active. CHRONOS-2 is a randomized, double-blind phase III Study of copanlisib versus placebo in patients with rituximab-refractory indolent NHL. ${ }^{34}$ CHRONOS-3 and 4 aim to evaluate efficacy of copanlisib in combination with other therapies for relapsed iNHLs (with rituximab and standard chemo-immunotherapy RCHOP or BR, respectively).

\section{Administration}

CHRONOS-1 study established that copanlisib can be administered in the outpatient setting at $60 \mathrm{mg}$ intravenously infused over $1 \mathrm{~h}$ on days 1,8 , and 15 of a 28-day cycle with treatment continuation until unacceptable toxicity or disease progression. There is no requirement for premedications.

Given the predominant hepatic elimination of copanlisib, ${ }^{24}$ concomitant use of copanlisib with a strong CYP3A inducer should be avoided and the package insert recommends a dose decrement to $45 \mathrm{mg}$ in this setting. Manufacturers also recommend a dose decrease to $45 \mathrm{mg}$ in case with moderate hepatic impairment (Child Pugh Class B). The pharmacokinetics of copanlisib in severe hepatic (Child Pugh Class C) and renal impairment (creatinine clearance $<30 \mathrm{~mL} / \mathrm{min}$, with or without dialysis) are unknown and no dosage adjustments provided in the package insert. ${ }^{23}$

\section{Safety Profile}

Zinzani et al published a pooled safety analyses from eight phase I and phase II studies of copanlisib in 364 patients with hematologic malignancies, out of which $42 \%$ ( $n=$ 153) had FL. ${ }^{35}$ These updated data reported all-grade TEAEs in $97.8 \%$ of patients with grade 3 or 4 TEAEs in

Table I Ongoing Phase III Trials Studying Copanlisib in NHL

\begin{tabular}{|c|c|c|c|c|c|c|c|c|}
\hline NCT Identifier & Phase & Agent(s) & Indication & $\begin{array}{l}\text { Actual Study } \\
\text { Start date }\end{array}$ & $\begin{array}{l}\text { Estimated } \\
\text { Study } \\
\text { Completion }\end{array}$ & $\begin{array}{l}\text { Sponsorl } \\
\text { Country }\end{array}$ & Status & $\begin{array}{l}\text { Planned } \\
\text { Accrual/ } \\
\text { Actual } \\
\text { Enrollment }\end{array}$ \\
\hline $\begin{array}{l}\text { NCT023690I6 } \\
\text { CHRONOS-2 }\end{array}$ & III & $\begin{array}{l}\text { Copanlisib vs } \\
\text { placebo }\end{array}$ & $\begin{array}{l}\text { Rituximab- } \\
\text { refractory } \\
\text { iNHL, 3rd } \\
\text { line }\end{array}$ & $\begin{array}{l}\text { September 22, } \\
2015\end{array}$ & $\begin{array}{l}\text { November 30, } \\
2020\end{array}$ & $\begin{array}{l}\text { Bayer/ } \\
\text { International }\end{array}$ & $\begin{array}{l}\text { Active/ } \\
\text { Not } \\
\text { recruiting }\end{array}$ & $189 / 25$ \\
\hline $\begin{array}{l}\text { NCT02367040 } \\
\text { CHRONOS-3 }\end{array}$ & III & $\begin{array}{l}\text { Copanlisib + } \\
\text { rituximab vs } \\
\text { placebo + } \\
\text { rituximab }\end{array}$ & $\begin{array}{l}\text { Relapsed } \\
\text { iNHL }\end{array}$ & August 3,2015 & $\begin{array}{l}\text { September 30, } \\
2021\end{array}$ & $\begin{array}{l}\text { Bayer/ } \\
\text { International }\end{array}$ & $\begin{array}{l}\text { Active/ } \\
\text { Not } \\
\text { recruiting }\end{array}$ & $514 / 458$ \\
\hline $\begin{array}{l}\text { NCT02626455 } \\
\text { CHRONOS-4 }\end{array}$ & III & $\begin{array}{l}\text { Copanlisib + } \\
\text { chemo- } \\
\text { immunotherapy } \\
(B R \text { or RCHOP) vs } \\
\text { placebo + BR/ } \\
\text { RCHOP }\end{array}$ & $\begin{array}{l}\text { Relapsed } \\
\text { iNHL }\end{array}$ & January 6,2016 & April 12, 2022 & $\begin{array}{l}\text { Bayer/ } \\
\text { International }\end{array}$ & $\begin{array}{l}\text { Active/ } \\
\text { Not } \\
\text { recruiting }\end{array}$ & $724 / 551$ \\
\hline
\end{tabular}


$51.4 \%$ and $24.7 \%$ of patients, respectively. Of these, copanlisib-related TEAEs of all grades were reported for $88.7 \%$ patients with grade 3 and 4 events occurring in $54.1 \%$ and $18.4 \%$ of patients, respectively. The most common ( $\geq 20 \%$ ) TEAEs (all grade/g3/g4) were hyperglycemia (50.5\%/28.3\%/4.4\%), hypertension (38.7\%/29.1\%/0\%), and diarrhea $(37.1 \% / 4.9 \% / 0 \%)$. Hyperglycemia and hypertension were infusion-related, transient, and manageable. Of note, AEs were commonly reported early with a greater incidence occurring at $\leq 180$ days with no increased incidence of grade 3 or higher events with prolonged exposure, apart from diarrhea. Patients treated for more than 1 year exhibited a similar adverse event trend as 22 patients who were treated for more than 2 years, despite prolonged exposure in the latter group, indicating low rates of cumulative toxicity and a favorable long-term safety profile. Diarrhea was an exception, as mentioned above, and the incidence of grade 3 diarrheal events increased with prolonged exposure, occurring at $8.9 \%$ at $\leq 180$ days, $7.1 \%$ between 181 and 360 days, and increasing to $12.5 \%$ at $\geq 361$ days. Pneumonitis was infrequent (all grade and grade 3 or higher $5.2 \%$ and $2.7 \%$, respectively, without a significant increase in incidence in patients treated for more than 1 year $(10.7 \% / 3.6 \%)$. Serious adverse events (SAEs) trends paralleled TEAEs. As high as $10.7 \%$ patients $(n=39)$ died either during copanlisib treatment or within 35 days post discontinuation of treatment; however, that was most commonly due to disease progression (4.7\%) and not deemed a drug-effect. In distinction to inflammatory AEs noted with oral PI3K inhibitors, there were no grade 4 late-onset colitis, hepatotoxicity, or other intestinal toxicity that occurred after 6 months of copanlisib treatment. Overall, these data provide evidence for the manageable safety profile of long-term copanlisib treatment, with no late-onset toxicities or worsening of severity of TEAEs, few severe gastrointestinal TEAEs, and no new unexpected safety signals.

\section{Hyperglycemia}

Transient hyperglycemia is a predictable, on-target effect of PI3K $\alpha$ inhibition due to abrogation of downstream insulin receptor signaling. ${ }^{17}$ The p110 $\alpha$ isozyme and AKT2 mediate insulin-driven glucose uptake in muscle, liver, and fat cells, mainly attributable to the translocation of glucose transporters (GLUT) to the plasma membrane. As a result, acute, systemic inhibition of $\mathrm{PI} 3 \mathrm{~K} \alpha / \mathrm{AKT}$ blocks insulin action, preventing glucose uptake in adipose tissue and skeletal muscle, and promoting hepatic gluconeogenesis through glycogenolysis. The resultant hyperglycemia is transient due to insulin feedback and compensatory insulin release from the pancreas resulting in normalization of glucose levels. , $^{55,36}$

Grade 3 or 4 hyperglycemia (blood glucose $250 \mathrm{mg} / \mathrm{dL}$ or greater) occurred in $32.7 \%$ of 364 patients with hematologic malignancies treated with copanlisib, with serious hyperglycemic events occurring in $4.1 \%$ of patients. ${ }^{37}$ Infusion-related hyperglycemia, peaking about 5 to 8 $\mathrm{h}$ post copanlisib infusion, was noted in both diabetic and non-diabetic patients in the phase I first-in-human trial of copanlisib by Patnaik et al as well as the phase 1 pharmacodynamic study by Morschhauser et al. ${ }^{26,38}$ Plasma glucose levels returned to baseline within $24 \mathrm{~h}$. Similar results regarding onset, peak, and nadir of glucose elevation were demonstrated in the phase IIB CHRONOSI study. ${ }^{32}$ Only $17.7 \%$ of patients exhibited elevated blood glucose levels 1 day after infusion. ${ }^{23}$ The prevalence of hyperglycemia decreases after the 1 st cycle $(48.48 \%)$ and remains relatively constant (6.9 to $16.1 \%$ ) during subsequent cycles which is possibly due to down-regulation of alpha receptors and development of glycemic tolerance. Hemoglobin A1c (HgbA1c) values do show an overall increase during copanlisib treatment indicating a cumulative effect. The mean HgbAlc values increment was 0.64 in diabetics and 0.50 in non-diabetics. ${ }^{39}$ However, HgbA1c values 3 months after drug discontinuation were not reported in this study (the time when posttreatment changes in glycated hemoglobin would be expected to emerge). ${ }^{35}$ In pooled analyses, of 155 patients with baseline $\mathrm{HbA1c}<5.7 \%, 10 \%$ had $\mathrm{HbA} 1 \mathrm{c}>6.5 \%$ after about 15 cycles; however, the time to normalization of HgbA1c is unclear. $^{23}$ Reassuringly, hyperglycemia, both as a TEAE and SAE, emerges early during the treatment course (higher incidence $\leq 180$ days) and there is no increased incidence of grade 3 or higher events with prolonged exposure. ${ }^{37}$ In patients with pre-existing diabetes ( $n=20$ in CHRONOS-I) however, incidence of all-grade hyperglycemia was nearly twice that seen in the nondiabetic cohort ( $85 \%$ vs $44.3 \%$ ) likely due to blunting of the insulin feedback loop from insulin resistance, with $35 \%(n=7)$ patients developing grade 4 hyperglycemia and two discontinuing treatment due to it. ${ }^{39}$ Interestingly, the ORR, PFS, and median DOR were lower in the diabetic subset as compared to the non-diabetic subset $(40 \%$ vs $>60 \%$; 7.2 months vs 13.8 months; 7.1 months vs 14.9 months, respectively); however, the study was not powered to detect such an efficacy difference. 
In clinical trials, stringent glucose monitoring was done pre- and post-copanlisib infusion, and monitoring was continued on days 2 and 3. In the phase I study, patients also fasted for $8 \mathrm{~h}$ prior to copanlisib infusion and up to $3 \mathrm{~h}$ post-infusion. ${ }^{26}$ Cheson et $\mathrm{al}^{35}$ recommended against immediate post-infusion glucose monitoring in nondiabetic patients, although blood glucose levels could be re-checked $24 \mathrm{~h}$ post infusion at the clinician's discretion. The use of insulin for management of infusion-related hyperglycemia is not recommended in insulin-naïve, nondiabetic patients given transient nature of hyperglycemia which could normalize before onset of action of insulin and risk of hypoglycemia. In CHRONOS-I, insulin was administered to 17 out of 84 patients to manage infusionrelated hyperglycemia; however, owing to hypoglycemic events following short-acting insulin use, further recommendations were to use only intravenous hydration in insulin-naive patients. ${ }^{35}$

In patients at risk for diabetes, including those with obesity and/or a family history of diabetes, $\mathrm{HbAlc}$ screening is recommended to be performed prior to treatment to identify prediabetic or uncontrolled diabetic patients. In newly or previously diagnosed diabetic patients, it is imperative to ensure adequate glycemic control prior to initiation of copanlisib which requires close consultation with the patient's primary care provider or endocrinologist. Consideration should be given to use oral diabetic agents, in particular, sodium-glucose co-transporter-2 (SGLT-2) inhibitors and adherence to American diabetic association (ADA) recommended diabetic diet should be encouraged pre-and post-infusion. Post-infusion glucose monitoring for several hours is recommended in diabetic patients; however, the optimal duration of monitoring has not yet been determined. ${ }^{35}$

\section{Role of Ketogenic Diet, Metformin, and SGLT-2 Inhibitors}

It has been hypothesized that the insulin feedback induced by PI3K inhibitors may reactivate the PI3K-mTOR signaling axis in tumors, thereby compromising treatment effectiveness. Hopkins et al, in mouse tumor models, reported on dietary and pharmaceutical strategies aimed at preventing insulin feedback and in turn, enhancing the efficacy and reduce the toxicity of PI3K inhibitors. ${ }^{36,40}$ These included the antidiabetic drug metformin, which increases insulin sensitivity and reduces insulin levels; sodium glucose cotransporter 2 (SGLT2) inhibitors, which reduce glucose reabsorption in kidney tubules; and a ketogenic diet, which depletes glycogen stores and thus limits the acute hepatic glucose efflux upon PI3K inhibition. In preclinical animal models, SGLT2 inhibitors and a ketogenic diet prevented insulin feedback and enhanced the antitumor effect of PI3K pathway inhibitors in both PIK3CAmutant and PIK3CA wild-type tumors. Although, yet to be tested clinically, should a diabetic patient need pharmacotherapy for adequate pre-treatment glucose control, strong consideration should be given to initiation of SGLT-2 inhibitors.

Based on the aforementioned data, the FDA-approved package insert recommends to withhold copanlisib in patients with a pre-infusion fasting plasma glucose of $\geq 160 \mathrm{mg} / \mathrm{dL}$ or a random glucose of $\geq 200 \mathrm{mg} / \mathrm{dL}$ until the fasting glucose is $\leq 160 \mathrm{mg} / \mathrm{dL}$ or the random glucose is $\leq 200 \mathrm{mg} / \mathrm{dL}$. For those patients with a post-dose blood glucose $\geq 500 \mathrm{mg} / \mathrm{dL}$, on first occurrence, copanlisib should be withheld until the fasting glucose is $\leq 160 \mathrm{mg} /$ $\mathrm{dL}$ or the random blood glucose is $\leq 200 \mathrm{mg} / \mathrm{dL}$. Dose reductions (60 mg to $45 \mathrm{mg}$ and then to $30 \mathrm{mg}$ ) or discontinuation should only be considered in situations of severe or recurrent events or if progressive metabolic derangement persists after therapeutic interventions have been attempted for a sufficient duration per a National Cancer Institute task force. ${ }^{41}$

\section{Hypertension}

In updated pooled analyses of patients with hematologic malignancies treated with copanlisib, transient, infusionrelated hypertension of all grades occurred in $38.7 \%$ (n-364) of patients. Grade 3 hypertension was seen in $29.1 \%$ of patients with no grade 4 events. ${ }^{37}$

Hypertension was not a previously reported $\mathrm{AE}$ for other pan-PI3K inhibitors. In the phase I trials, multiple factors were posited by the authors to account for this $\mathrm{AE}$ including frequent monitoring, dysregulation of endothelial-derived vasoconstriction, and dilators based on peripheral vasoconstriction noted in laboratory animals following copanlisib administration, and acute insulin elevation and resultant vasoconstriction due to PI3K blockade. ${ }^{26,27}$

All-grade hypertension was noted in $43.9 \%$ of hypertensive patients in CHRONOS-1-part B and was principally grade $3(39.0 \%)$, compared to $23.8 \%$ and $17.8 \%$, respectively, in non-hypertensives. No grade 4 hypertension events were noted and 1 patient discontinued treatment due to grade 2 hypertension. There were 2 grade 3 cardiac-related events (atrial fibrillation and left 
ventricular dysfunction) and one grade 4 event (arrhythmia) in the hypertensive group. ${ }^{39}$ The authors also noted a longer PFS and DOR in the hypertensive cohort as compared to the non-hypertensive patients (19 and 22.6 mos vs 11.3 and 10.9 mos, respectively).

Similar to hyperglycemia, hypertension associated with copanlisib appears to be infusion-related and consistent with an on-target effect. Blood pressures (BP) peak $2 \mathrm{~h}$ post-infusion and normalize within $24 \mathrm{~h}^{23,35}$ The mean change of systolic and diastolic BP from baseline to $2 \mathrm{~h}$ post-infusion on Cycle 1 Day 1 was $16.8 \mathrm{mmHg}$ and $7.8 \mathrm{mmHg}$, respectively. The mean BP usually starts to decrease approximately $2 \mathrm{~h}$ post-infusion and BP may remain elevated for 6 to $8 \mathrm{~h}$ after the start of the infusion.

Optimal BP control should be achieved before initiating copanlisib with dietary or pharmacologic measures. In CHRONOS-I, antihypertensive use was permitted based on investigator clinical judgment. ${ }^{32}$ It is recommended to monitor BP pre- and post-infusion. For patients with a pre-dose $\mathrm{BP}$ of $\geq 150 / 90 \mathrm{~mm} \mathrm{Hg}$, the recommendation is to hold copanlisib until 2 consecutive readings of $<150 / 90 \mathrm{~mm} \mathrm{Hg}$ have been achieved, measured at least 15 min apart. The decision of whether to treat copanlisib-induced hypertension with antihypertensive therapy should be individualized based on baseline blood pressure, the severity of blood pressure elevation during treatment, and preexisting cardiovascular risk factors (eg, diabetes or chronic kidney disease) or cardiovascular disease (eg, ischemic heart disease, stroke or transient ischemic attack, peripheral vascular disease, or heart failure). Given the short, anticipated duration of elevated blood pressure secondary to copanlisib treatment, short-acting antihypertensives are preferred. For patients with a post-dose blood pressure of $<150$ / $90 \mathrm{~mm} \mathrm{Hg}$, if antihypertensive therapy was not required, copanlisib should be continued at the previous dose. However, if blood pressure remains uncontrolled $(\geq 150$ / $90 \mathrm{~mm} \mathrm{Hg}$ ) despite initiation or optimization of antihypertensive therapy, copanlisib can be reduced from 60 to $45 \mathrm{mg}$, or from 45 to $30 \mathrm{mg}$. ${ }^{23,35}$

Whereas the hypertensive cohort exhibited similar ORR of $61 \%$ vs $60.4 \%$; the PFS and DOR appeared to be longer at 19 months vs 11.3 months, and 22.6 months vs 10.9 months, respectively.

In summary, treatment-related hyperglycemia and hypertension are common infusion-related side effects of copanlisib with a greater incidence in those patients with these pre-existing conditions; however, these were mostly lower grade and manageable. Hyperglycemic events in diabetic patients were not severe, not associated with ketoacidosis states and did not impact overall glycemic control with only minor increases in A1c values from baseline. Treatment discontinuations due to these AEs were uncommon. Overall, data support the low likelihood of these adverse events translating into long-term consequences and support use of copanlisib in indolent lymphoma patients with well-controlled diabetes or hypertension.

\section{Diarrhea}

PI3K activation in leukocytes is predominantly mediated by $\mathrm{p} 110 \gamma$ and $\mathrm{p} 110 \delta$ isoforms which produce phosphatidylinositol $(3,4,5)$-trisphosphate (PIP3) following receptor engagement. This signal transduction can act as an activation or dampening switch for immune response depending on the receptor, the cell type, and the degree of PI3K activation. $\mathrm{p} 110 \alpha$ and $\mathrm{p} 110 \beta$ are also expressed in immune cells; however, their roles are restricted. ${ }^{5}$ Overall, PI3K inhibition causes immune reprogramming and a proinflammatory effect however these effects are predominantly mediated by the $\mathrm{p} 110 \delta$ isoform.

Inactivation of $\mathrm{p} 110 \delta$ impairs differentiation of effector CD4+ and CD8+ T cells, yet also impairs regulatory T-cell (Treg) function. This Treg defect has been thought to be responsible for the autoimmune colitis that develops in p1108-deficient mice and likewise, to mediate diarrhea and colitis which are frequent side effects of idelalisib (a PI3K $\delta$ inhibitor). ${ }^{5}$ The principal action of copanlisib on the $\alpha$ and $\gamma$ isoforms as well the intravenous route of administration could contribute to the lower incidence of GI toxicity seen with this drug.

In pooled analyses, all-grade diarrhea occurred in $37.1 \%$ of 364 patients treated with copanlisib; however, grade 3 events were significantly lower at $4.9 \%$ in comparison to $13-14 \%$ seen with idelalisib and duvelisib. ${ }^{21,31}$ There were no grade 4 diarrhea events. ${ }^{37}$ This finding is in contrast to the oral agents idelalisib and duvelisib where grade 3 diarrheal events were seen in $14 \%$ and $18 \%$ of patients, respectively. ${ }^{35}$ Also, both of these oral agents carry FDA Black Box warnings for severe diarrhea or colitis. Interestingly, the incidence of diarrhea as a grade 3 event did increase with prolonged exposure to copanlisib with a rate of $3 \%$ at $\leq 180$ days, $4.2 \%$ at $181-360$ days, and $12.5 \%$ at $>360$ days. This trend is unlike what has been noted for hyperglycemia and hypertension. The difference could be due to the fact that hypertension and 
hyperglycemia are on-target effects while diarrhea is likely due to durable immune perturbances caused by copanlisib.

In patients with grade 3 diarrhea, copanlisib should be withheld until diarrhea resolves to grade 1 or better and the drug should be restarted at $45 \mathrm{mg}$. If diarrhea of grade 3 or worse recurs, copanlisib should be discontinued.

\section{Infections}

Due to the high incidence of infections seen with idelalisib, close monitoring for infectious complications was done in CHRONOS-I. Copanlisib was found to be associated with relatively low rates of myelosuppression and pulmonary infections in the trial. All grade, grade 3, and grade 4 neutropenia in pooled analysis was noted to be $23.1 \%, 9.3 \%$, and $9.6 \%$, respectively. Of 142 patients in the CHRONOS-1 Part B trial, there were 2 (1.4\%) patients with a grade 3 upper respiratory infection; $9.9 \%$ of patients had grade 3 or 4 (1.4\% grade 4$)$ pneumonia, and there was a single ( $0.7 \%$ of patients) death from lung infection that was considered to be treatment-related. Prophylaxis was not routinely given to subjects receiving copanlisib as a monotherapy in CHRONOS-1, although 18 patients did receive it at the investigator's discretion. In pooled analyses, pneumonia was the most frequent SAE with a frequency of pneumonia $6.0 \%$ (all grade) and 5.5\% (grade 3 or higher). Given infrequency of pneumonia during therapy, routine prophylaxis is not recommended (unlike idelalisib); however, absolute neutrophil counts are recommended to be monitored weekly, and treatment should be withheld if the absolute neutrophil count (ANC) is less than $0.5 \times 10^{3}$ cells $/ \mathrm{mm} 3 .{ }^{35}$ When ANC is greater than $0.5 \times 10^{3}$ cells $/ \mathrm{mm}^{3}$, it is recommended to resume copanlisib at the previous dose. However, if the grade 4 neutropenia recurs, a dose-reduction to $45 \mathrm{mg}$ is recommended. Granulocyte colony-stimulating factor (G-CSF) has not been routinely used in clinical trials and use is not standardized. If a patient has shown a good response to copanlisib, G-CSF could be used to maximize treatment duration especially given the $\mathrm{R} / \mathrm{R}$ setting and decisions should be individualized for the patients.

\section{Early Progressing FL}

Recent data have highlighted that the strongest predictor of long-term FL outcomes is the length of first remission after front-line therapy. Patients with disease progression within 24 months of completing induction chemoimmunotherapy with R-CHOP, R-CHOP like regimens, or rituximab-based immunotherapy doublets (POD24) have inferior OS compared with those with longer remission durations. $^{42,43}$ Idelalisib has previously been shown to have clinical activity in POD24 FL patients $(n=46$; POD24=37) with an ORR of 56.7\%, including 5 (13.5\%) CRs and mPFS of $11.1 \mathrm{mos},{ }^{44}$ which was equivalent to that noted in non-POD24 patients (ORR 54\%). Similarly, exploratory analysis from the CHRONOS-1 data showed robust activity of copanlisib in POD24 patients $(n=104$; POD24=37) and comparable to that noted in the nonPOD24 cohort ( $\mathrm{n}=68$; ORR $60.3 \%) .{ }^{45}$ ORR and CR rates were slightly higher than that seen with idelalisib at $58.9 \%$ and $17.7 \%(n=6)$ however given small numbers in both studies, meaningful comparisons cannot be drawn. mPFS and mOS were similar in both groups: 11.3 vs $10.8 \mathrm{mos}$ and 38.3 vs $31.0 \mathrm{mos}$, in non-POD24 and POD24, respectively. Results were similar in patients previously treated with R-CHOP. These data emphasize that the efficacy of copanlisib is not impacted by POD24 status and can offset the inferior survival noted in this high-risk group in previous trials and this finding should be further characterized in larger patient samples to ensure generalizability.

\section{Discussion}

PI3K inhibitors are approved for treatment of $\mathrm{R} / \mathrm{R}$ FL in the third-line setting. Copanlisib is unique in this class in that it is a pan-class I PI3K inhibitor, with preferential inhibitory activity against the $\mathrm{PI} 3 \mathrm{~K} \alpha$ and $\mathrm{PI} 3 \mathrm{~K} \delta$ isoforms. It is an intravenous drug that is administered weekly, whereas the other FDA-approved PI3K inhibitors (idelalisib and duvelisib) are oral formulations with twice-daily dosing.

Despite the intravenous route of administration, copanlisib provides an advantage over the oral agents given an extremely favorable toxicity profile and lack of cumulative, progressive, long-term toxicities, while maintaining efficacy. The intermittent dosing schedule has been designed to achieve optimal target inhibition within the tumor while sparing normal tissue, a strategy which was shown to be more effective than continuous dosing in mice bearing breast cancer xenografts. Weekly dosing along with isoform inhibition preference results in the distinctive AE profile of copanlisib and confers an advantage over the approved oral PI3K inhibitors - idelalisib and duvelisib. $\mathrm{PI} 3 \mathrm{~K} \delta$ inhibition is linked to myelosuppression, transaminitis, and autoimmune toxicities and both idelalisib and duvelisib are associated with a prohibitive, treatmentlimiting toxicity and carry boxed warnings. Immunosuppression-related toxic effects, including 
infections, have been noted to be higher in real-world outcomes study of idelalisib, as compared to those observed in trials, likely due to frequent dose reductions and exclusion of patients with ongoing infections in the trial setting. ${ }^{20}$ This toxicity profile counterweighs the feasibility of oral agents.

Dual PI3K $\alpha$ and $\delta$ inhibition is also an astute strategy for overcoming PI3K resistance. Iyengar et al studied PI3K class IA isoforms in primary patient mantle cell lymphoma samples and demonstrated that although p110 $\delta$ was widely overexpressed, p110 $\alpha$ expression was variable, and significant increases occurred with disease progression. $^{46,47}$ Further, combined inhibition of p110- $\alpha$ and $\mathrm{p} 110-\delta$ isoforms was noted to be a more effective strategy for inhibiting constitutive PI3K activation in cell lines. Whole-exome sequencing identified PI3KCA gainof-function mutations (N345K, P539R, E970K) in 3 independently generated idelalisib-resistant WSU-FSCCL FL cell line clones and compensatory activation in SFK and WNT pathways indicating a mechanistic role of $p 110 \alpha$ in resistance. ${ }^{48}$ Hence, simultaneous targeting of both PI3K- $\alpha$ and PI $3 \mathrm{~K}-\delta$ could bypass this resistance mechanism.

Regarding concerns of financial toxicity incurred on patients due to intravenous dosing, a budget impact model noted that over a 1-year period, addition of copanlisib to a formulary resulted in a small increase in total budget of $\$ 242,641$, corresponding to $\$ 0.02$ per patient per month. This assessment accounted for a concurrent increase in the use of obinutuzumab plus bendamustine and lenalidomide plus rituximab. The analysis concluded that the addition of copanlisib was an affordable option for payers thus alleviating, to some extent, concerns of financial toxicity incurred on the patients. ${ }^{49}$ The more favorable safety profile of copanlisib compared to other agents in its class without late-onset or treatment-limiting toxicities makes it an agent with immense clinical utility and significance in the third-line setting.

Optimal sequencing of therapies in $\mathrm{R} / \mathrm{R}$ FL remains unknown. Existing and evolving prognostic models utilize clinical, $^{50,51}$ gene mutation status ${ }^{52}$ or gene expression profiling $^{53}$ of the tumor microenvironment to predict FL outcomes. The prognostic value of the clinicogenetic risk models is dependent on the therapeutic regimen. These perform inadequately in predicting early progression ${ }^{42}$ and are not prognostic in patients who receive chemofree regimens upfront. ${ }^{54}$ A 23 -gene predictive score developed in the post-rituximab era was able to identify a highrisk FL population which was at an increased risk of progression after frontline rituximab-chemotherapy, independent of rituximab maintenance and FLIPI score. ${ }^{53}$ However, given that novel agents can interfere with gene expression signatures in both tumor B-cells and their microenvironment, its validity in this scenario needs further investigation.

In the absence of a universal prediction model, positioning of copanlisib in the $\mathrm{R} / \mathrm{R}$ setting is dependent on individualized risk-benefit assessment which should account for patient's disease status whether relapsed or refractory, tumor burden, presence or absence of transformation, performance status, and co-existing medical conditions especially diabetes or hypertension. Low-risk patients (non-chemo-refractory, non-POD24, low tumor burden, etc.) could benefit from shorter duration and less toxic therapy whereas high-risk patients should ideally be referred for clinical trials including those evaluating chimeric-antigen receptor modified T (CAR-T) cell therapy. ${ }^{55}$ Anti-CD19 CAR-T cell therapy has shown high ORR and $\mathrm{CR}$ rates in both progressive and transformed FL and could be considered for high-risk R/R FL patients especially those who are young and with high tumor burden, given increased durable complete remission rates. ${ }^{56}$ Copanlisib could be considered in older patients desiring to avoid the side-effects associated with lymphodepleting chemotherapy or cytokine release syndrome seen with CAR-T cells.

\section{Future Directions}

Acquired and inherent drug resistance is always a potential concern with monotherapy leading to further investigations of copanlisib as combination therapy. Based on preclinical studies, potential drug combinations include chemotherapy, immune-checkpoint inhibitors (ICIs), bcl2 inhibitors, and other kinase inhibitors. In vitro studies of idelalisib showed augmented DNA damage when it was used with bendamustine providing a therapeutic rationale for administration of PI3Kis concomitantly with chemotherapy. ${ }^{57}$ CHRONOS-4 is investigating use of copanlisib with standard chemoimmunotherapy (B-R or R-CHOP) and a phase 1 study (NCT04156828) is assessing R-CGD (carboplatin, gemcitabine, and dexamethasone) with copanlisib for $\mathrm{R} / \mathrm{R}$ grade $3 \mathrm{~b} F L$ and DLBCL. The role of ICIs is also being examined in lymphoid malignancies and the anti-PD1 antibody nivolumab has shown an ORR of $40 \%$ as a single-agent in R/R FL. ${ }^{58}$ $\mathrm{PI} 3 \mathrm{~K} \delta$ inhibition is thought to abrogate T-cell immune tolerance to cancer, leading to potential for combination 
with ICIs. ${ }^{59}$ A study of duvelisib with immune checkpoint (anti-PD-1, RMP1-14) or co-stimulatory (anti-OX40, clone OX86) antibodies in a murine B-cell lymphoma model showed that the combination of duvelisib with antiPD1 antibodies caused synergistic tumor regression as well as development of immune memory that prohibited new tumor growth upon oncogenic rechallenge in mice treated with the combination. ${ }^{60}$ The lack of autoimmune AEs with copanlisib as compared to idelalisib or duvelisib makes it a more favorable PI3K inhibitor for use with ICIs and a phase $1 \mathrm{~B}$ trial is assessing the safety and efficacy of nivolumab in combination with copanlisib in advanced solid tumors and lymphomas. ${ }^{61}$

Clinical trials utilizing combinations of idelalisib with immunomodulatory agents, anti-CD20 monoclonal antibodies and, kinase inhibitors have shown undue toxicities. The phase 1 Alliance trial- A051202, evaluating the combination of idelalisib, lenalidomide, and rituximab in $\mathrm{R} / \mathrm{R} / \mathrm{FL}$ had to be terminated due to dose-limiting rash, transaminitis, and infections. ${ }^{62}$ A trial of idelalisib with bendamustine and rituximab was conducted in $\mathrm{R} / \mathrm{R}$ chronic lymphocytic leukemia exhibited increased rates of serious adverse events of febrile neutropenia, pneumonia, and pyrexia in the idelalisib cohort versus placebo, including 6 deaths attributed to infections with idelalisib. ${ }^{63}$ Similarly, combination of idelalisib with a SYK inhibitor, entospletinib, resulted in high rates of treatment-emergent, life-threatening, and fatal pneumonitis. ${ }^{64}$ With the improved safety profile of copanlisib, these combinations could be revisited.

Another promising research direction is combining copanlisib with the bcl-2 inhibitor venetoclax, supported by preclinical data showing synergy between PI3K $\alpha / \delta$ inhibition with BCL-2 blockade in some DLBCL subtypes. Concurrent bcl-2 and PI3K inhibition has also been able to overcome acquired venetoclax resistance in vitro. ${ }^{65} \mathrm{~A}$ recent cell-viability screen identified venetoclax as the strongest partner for copanlisib in B-cell lymphomas ${ }^{66}$ and this preclinical foundation has led to the SAKK 66/18 phase 1 study (NCT03886649) exploring the combination of copanlisib and venetoclax in relapsed/refractory lymphomas.

The potential for translation of in vitro synergy to efficacious therapeutic combinations is promising and could lead to wider applications of copanlisib in FL.

\section{Newer PI3k Inhibitors}

The established efficacy of PI3K inhibitors in lymphoid malignancies has been often overshadowed by their adverse event profile (Table 2). There is a need for safe and tolerable PI3K inhibitors with equivalent efficacy and improved feasibility. This has led to the development of umbralisib (TGR-1202) and ME-40, both of which are oral PI3Kis with once daily administration schedules. Umbralisib is a dual inhibitor of $\mathrm{PI} 3 \mathrm{~K} \delta$ and casein kinase-1- $\varepsilon$ which has shown a $53 \%$ ORR in $R / R$ FL in a phase 1 dose escalation trial $(\mathrm{FL} n=22) .{ }^{67}$ Updated safety data from the UNITY trial show that, similar to the idelalisib and duvelisib studies, the most frequent AEs were diarrhea (44\%), nausea (39\%), and fatigue $(35 \%) ;{ }^{68}$ however, the incidence of grade 3 or higher adverse events was lower (2-9\% grade $\geq 3$ diarrhea on the umbralisib monotherapy study. Of note, late onset diarrhea or colitis commonly seen with first-generation $\mathrm{PI} 3 \mathrm{~K} \delta$ inhibitors was uncommon. In patients who had been on umbralisib for at least 6 months $(n=167$, median umbralisib exposure 15.6 mos; range 6.4-60.6 mos), the incidence of diarrhea remained low with a $25 \%$ incidence of all grade diarrhea of which only $7 \%$ were grade 3 or higher. Umbralisib is currently being studied in UNITY-CLL Phase 3 randomized trial (NCT02612311) and UNITY-NHL Phase 2b randomized trial (NCT02793583).

ME-401 is a PI3Ki selective for p110 $\delta$ and is currently being investigated in the phase $1 \mathrm{~b}$ (NCT02914938) and II (TIDAL study, NCT03768505) setting. The phase $1 \mathrm{~b}$ study is evaluating ME-401 as both monotherapy and in combination with rituximab or the BTK inhibitor zanubrutinib with a continuous (CS) and intermittent (IS) dosage schedule. Preliminary data have shown an ORR of $83 \%$ with ME-401 monotherapy in R/R FL. ${ }^{69}$ In keeping with the lower toxicity of intermittent PI3K inhibition, the IS dosing of ME-401 had a lower rate of immune-mediated AEs as compared to CS (11\% vs 30\%, respectively) and there was a potential to salvage disease progressions on IS by switching to $\mathrm{CS}^{70}$

Intermittent PI3K inhibition seems to be a key factor in reducing adverse events while maintaining efficacy. The investigation of the newer oral PI3Kis could not only prove superior to copanlisib in terms of their safety profile and ease of administration but also pave the way for exploration of similar, intermittent schedules for the existing oral PI3K inhibitors.

\section{Conclusions}

Copanlisib provides a significant advantage over the oral PI3K inhibitors due to its tolerability; however, newer oral agents including those with an intermittent dosing schedule could prove more advantageous. Combinations with 
Table 2 Efficacy and Safety Profile of PI3K Inhibitors in FL

\begin{tabular}{|c|c|c|c|c|c|}
\hline & Copanlisib & Idelalisib & Duvelisib & Umbralisib & ME-40I \\
\hline $\begin{array}{l}\text { Current } \\
\text { indication(s) }\end{array}$ & $\begin{array}{l}\text { 3rd-line FL, } \\
\text { CLL, SLL }\end{array}$ & 3rd-line FL, CLL, SLL & CLL/SLL, 3rd-line FL & $\begin{array}{l}\text { Orphan drug FL (3rd line), } \\
\text { Experimental }\end{array}$ & Experimental \\
\hline $\begin{array}{l}\text { Mechanism of } \\
\text { action }\end{array}$ & $\mathrm{PI} 3 \mathrm{Ki}(\alpha, \delta)$ & $\mathrm{PI} 3 \mathrm{Ki}(\delta)$ & $\operatorname{PI} 3 \mathrm{Ki}(\delta, \gamma)$ & $\mathrm{PI} 3 \mathrm{Ki}(\delta), \mathrm{CKI}-\varepsilon$ & $\mathrm{PI3Ki}(\delta)$ \\
\hline Administration & Intravenous & Oral & Oral & Oral & Oral \\
\hline Study population & $\begin{array}{l}\geq 3 r d \text { line } \\
(F L, n=72)\end{array}$ & $\begin{array}{l}\geq 3 r d \text { line } \\
(F L, n=72)\end{array}$ & $\geq 2$ nd line $(F L, n=83$ ) & $\geq 2 n d$ line $(F L, n=17)^{59}$ & $\begin{array}{l}\geq 1 \text { line } F L \\
(n=48)^{62}\end{array}$ \\
\hline ORR (FL) & $54 \%$ & $54 \%$ & $42 \%$ & $53 \%$ & $79 \%$ \\
\hline CR (FL) & $8 \%$ & $8 \%$ & $1 \%$ & $12 \%$ & $26 \%$ \\
\hline Median PFS (FL) & II months & II months & 8.3 months $^{2}$ & N/A (Median DOR 9.3 months) & $\mathrm{N} / \mathrm{A}$ \\
\hline Black box warning & None & $\begin{array}{l}\text { Fatal and/or serious } \\
\text { toxicities: } \\
\text { - Hepatotoxicity } \\
(16-18 \%) \\
\text { - Severe diarrhea or coli- } \\
\text { tis (14-20\%) } \\
\text { - Pneumonitis (4\%) } \\
\text { - Infections (2I-48\%) } \\
\text { Intestinal perforation }\end{array}$ & $\begin{array}{l}\text { Fatal and/or serious: } \\
\text { - Infections (3l\%) } \\
\text { - Diarrhea or coli- } \\
\text { tis ( } 18 \%) \\
\text { - Cutaneous reac- } \\
\text { tions }(5 \%) \\
\text { Pneumonitis (5\%) }\end{array}$ & N/A & $\mathrm{N} / \mathrm{A}$ \\
\hline \multicolumn{6}{|l|}{$\begin{array}{l}\text { Select Grade } \geq 3 \\
\text { AEs }\end{array}$} \\
\hline $\begin{array}{l}\text { Hyperglycemia } \\
\text { (transient) }\end{array}$ & $40 \%$ & None reported & None reported & None reported & None reported \\
\hline $\begin{array}{l}\text { Hypertension } \\
\text { (transient) }\end{array}$ & $27 \%$ & None reported & None reported & None reported & None reported \\
\hline Diarrhea & $5 \%$ & $14 \%$ & $23 \%$ & $43 \%$ & $\begin{array}{l}30 \% \text { on CS } \\
11 \% \text { on IS }\end{array}$ \\
\hline \multicolumn{6}{|l|}{ Colitis } \\
\hline Pneumonitis & $5 \%$ & $16 \%$ & $5 \%$ & None reported & $\mathrm{N} / \mathrm{A}$ \\
\hline Lung infection & $13.7 \%$ & & & $13 \%$ & \\
\hline ALT increased & None reported & $19 \%$ & $8 \%$ & $6 \%$ & $1.8 \%$ \\
\hline AST increased & None reported & $12 \%$ & $6 \%$ & $7 \%$ & $1.8 \%$ \\
\hline
\end{tabular}

chemo-immunotherapy, immune-checkpoint inhibitors, or bcl-2 inhibitors could lead to expanded indications for copanlisib and are under study. A significant impediment to developing novel therapies in FL and developing rational therapeutic combinations is lack of accurate biomarkers which implies that most novel combinations being studied are relatively empiric. Studies are investigating the role of PI3K and macrophage activation gene expression profiles to predict responses to copanlisib which, if possible, at outset, would enable a risk-adapted decisionmaking approach. The intravenous dosing schedule of copanlisib and requirement for blood glucose and blood pressure monitoring does impact feasibility of administration in the outpatient setting and studies should explore a more pragmatic maintenance schedule after an initial loading period. In summary, copanlisib is a safe and 
efficacious addition to our therapeutic armamentarium against FL and should allow us to improve current and future outcomes of these patients.

\section{Disclosure}

Bruce D Cheson reports research funding to prior institution from AstraZeneca, Bristol-Myers-Squibb, Seattle Genetics, Trillium, TG Therapeutics, Abbvie, Pharmacyclics, and Epizyme. He also reports consulting and advisory boards for Symbio, Morphosys, Beigene, Karyopharm, TG Therapeutics, and Merck, outside the submitted work. The authors report no other potential conflicts of interest for this work.

\section{References}

1. Sundar H, Fakhri B, Fayad LE, et al. NCCN guidelines version 1.2020 B-cell lymphomas NCCN evidence blocks TM continue NCCN guidelines panel disclosures $\xi$ bone marrow transplantation $\ddagger$ hematology/hematology oncology $\mathrm{P}$ internal medicine $\dagger$ medical oncology $\neq$ pathology $¥$ patient advocacy $\S$ radiotherapy/radiation oncology * Discussion writing committee member. 2020.

2. Batlevi CL, Sha F, Alperovich A, et al. Follicular lymphoma in the modern era: survival, treatment outcomes, and identification of high-risk subgroups. Blood Cancer J. 2020;10(7):74. doi:10.1038/ s41408-020-00340-z

3. Ihle NT, Powis G. Take your PIK: phosphatidylinositol 3-kinase inhibitors race through the clinic and toward cancer therapy. Mol Cancer Ther. 2009;8(1):1-9. doi:10.1158/1535-7163.MCT-08-0801

4. Yuan TL, Cantley LC. PI3K pathway alterations in cancer: variations on a theme. Oncogene. 2008;27(41):5497-5510. doi:10.1038/onc.2008.245

5. Fruman DA, Chiu H, Hopkins BD, Bagrodia S, Cantley LC, Abraham RT. The PI3K pathway in human disease. Cell. 2017;170 (4):605-635. doi:10.1016/j.cell.2017.07.029

6. Pongas G, Cheson BD. PI3K signaling pathway in normal B cells and indolent B-cell malignancies. Semin Oncol. 2016;43(6):647-654. doi:10.1053/j.seminoncol.2016.11.011

7. Küppers R. Mechanisms of B-cell lymphoma pathogenesis. Nat Rev Cancer. 2005;5(4):251-262. doi:10.1038/nrc1589

8. Strout MP. Sugar-coated signaling in follicular lymphoma. Blood. 2015;126(16):1871-1872. doi:10.1182/blood-2015-08-665141

9. Amin R, Mourcin F, Uhel F, et al. DC-SIGN-expressing macrophages trigger activation of mannosylated IgM B-cell receptor in follicular lymphoma. Blood. 2015;126(16):1911-1920. doi:10.1182/blood2015-04-640912

10. Linley A, Krysov S, Ponzoni M, Johnson PW, Packham G, Stevenson FK. Lectin binding to surface Ig variable regions provides a universal persistent activating signal for follicular lymphoma cells. Blood. 2015;126(16):1902-1910. doi:10.1182/blood-2015-04-640805

11. Hiddemann W, Cheson BD. How we manage follicular lymphoma. Leukemia. 2014;28(7):1388-1395. doi:10.1038/leu.2014.91

12. Leseux L, Hamdi SM, Al Saati T, et al. Syk-dependent mTOR activation in follicular lymphoma cells. Blood. 2006;108 (13):4156-4162. doi:10.1182/blood-2006-05-026203

13. Mourcin F, Pangault C, Amin-Ali R, Amé-Thomas P, Tarte K. Stromal cell contribution to human follicular lymphoma pathogenesis. Front Immunol. 2012;3(SEP). doi:10.3389/fimmu.2012.00280

14. Dil N, Marshall AJ. Role of phosphoinositide 3-kinase p1108 in TLR4- and TLR9-mediated B cell cytokine production and differentiation. Mol Immunol. 2009;46(10):1970-1978. doi:10.1016/j. molimm.2009.03.010
15. Guo H, Samarakoon A, Vanhaesebroeck B, Malarkannan S. The p110 $\delta$ of PI3K plays a critical role in NK cell terminal maturation and cytokine/chemokine generation. $J$ Exp Med. 2008;205 (10):2419-2435. doi:10.1084/jem.20072327

16. Herman SEM, Gordon AL, Wagner AJ, et al. Phosphatidylinositol 3-kinase- $\delta$ inhibitor CAL-101 shows promising preclinical activity in chronic lymphocytic leukemia by antagonizing intrinsic and extrinsic cellular survival signals. Blood. 2010;116(12):2078-2088. doi:10. 1182/blood-2010-02-271171

17. Krause G, Hassenrück F, Hallek M. Copanlisib for treatment of B-cell malignancies: the development of a PI3K inhibitor with considerable differences to idelalisib. Drug Des Devel Ther. 2018;12:2577-2590. doi:10.2147/DDDT.S142406

18. Dong T, Liu Z, Zhao S, et al. The expression of CD9 and PIK3CD is associated with prognosis of follicular lymphoma. $J$ Cancer. 2015;6 (12):1222-1229. doi:10.7150/jca.11279

19. Yang Q, Modi P, Newcomb T, Quéva C, Gandhi V. Idelalisib: first-in-class PI3K delta inhibitor for the treatment of chronic lymphocytic leukemia, small lymphocytic leukemia, and follicular lymphoma. Clin Cancer Res. 2015;21(7):1537-1542. doi:10.1158/1078-0432.CCR-14-2034

20. Bird ST, Tian F, Flowers N, et al. Idelalisib for treatment of relapsed follicular lymphoma and chronic lymphocytic leukemia: a comparison of treatment outcomes in clinical trial participants vs medicare beneficiaries. JAMA Oncol. 2020;6(2):248-254. doi:10.10 01/jamaoncol.2019.3994

21. Flinn IW, Miller CB, Ardeshna KM, et al. DYNAMO: a Phase II study of duvelisib (IPI-145) in patients with refractory indolent non-hodgkin lymphoma. J Clin Oncol. 2019;37(11):912-922. doi:10.1200/JCO.18.00915

22. Liu N, Rowley BR, Bull CO, et al. BAY 80-6946 is a highly selective intravenous PI3K inhibitor with potent $\mathrm{p} 110 \alpha$ and $\mathrm{p} 110 \delta$ activities in tumor cell lines and xenograft models. Mol Cancer Ther. 2013;12 (11):2319-2330. doi:10.1158/1535-7163.MCT-12-0993-T

23. Fda, Cder. Highlights of prescribing information. [cited July 12, 2020]. Available from: www.fda.gov/medwatch.

24. Gerisch M, Schwarz T, Lang D, et al. Pharmacokinetics of intravenous pan-class I phosphatidylinositol 3-kinase (PI3K) inhibitor [14 C]copanlisib (BAY 80-6946) in a mass balance study in healthy male volunteers. Cancer Chemother Pharmacol. 2017 Sep;80(3):535-544. doi:10.1007/s00280-017-3383-9

25. Paul J, Soujon M, Wengner AM, et al. Simultaneous inhibition of $\mathrm{PI} 3 \mathrm{~K} \delta$ and $\mathrm{PI} 3 \mathrm{~K} \alpha$ induces $\mathrm{ABC}-\mathrm{DLBCL}$ regression by blocking BCR-dependent and -independent activation of NF- $\mathrm{KB}$ and AKT. Cancer Cell. 2017;31(1):64-78. doi:10.1016/j.ccell.2016.12.003

26. Patnaik A, Appleman LJ, Tolcher AW, et al. First-in-human phase I study of copanlisib (BAY 80-6946), an intravenous pan-class I phosphatidylinositol 3-kinase inhibitor, in patients with advanced solid tumors and non-Hodgkin's lymphomas. Ann Oncol. 2016;27 (10):1928-1940. doi:10.1093/annonc/mdw282

27. Doi T, Fuse N, Yoshino T, et al. A phase I study of intravenous PI3K inhibitor copanlisib in Japanese patients with advanced or refractory solid tumors. Cancer Chemother Pharmacol. 2017;79(1):89-98. doi:10.1007/s00280-016-3198-0

28. Shapiro GI, Bell-McGuinn KM, Molina JR, et al. First-in-human study of PF-05212384 (PKI-587), a small-molecule, intravenous, dual inhibitor of PI3K and mTOR in patients with advanced cancer. Clin Cancer Res. 2015;21(8):1888-1895. doi:10.1158/1078-0432. CCR-14-1306

29. Dreyling M, Morschhauser F, Bouabdallah K, et al. Phase II study of copanlisib, a PI3K inhibitor, in relapsed or refractory, indolent or aggressive lymphoma. Ann Oncol. 2017;28:2169-2178. doi:10.1093/ annonc/mdx289

30. Flinn IW, Kahl BS, Leonard JP, et al. Idelalisib, a selective inhibitor of phosphatidylinositol 3-kinase- $\delta$, as therapy for previously treated indolent non-Hodgkin lymphoma. Blood. 2014;123(22):3406-3413. doi:10.1182/blood-2013-11-538546 
31. Gopal AK, Kahl BS, Vos S, et al. PI3K $\delta$ inhibition by idelalisib in patients with relapsed indolent lymphoma. $N$ Engl J Med. 2014;370 (11):1008-1018. doi:10.1056/NEJMoa1314583

32. Dreyling M, Santoro A, Mollica L, et al. Phosphatidylinositol 3-kinase inhibition by Copanlisib in relapsed or refractory indolent lymphoma. J Clin Oncol. 2017;35(35):3898-3905. doi:10.1200/JCO.2017.75.4648

33. Dreyling M, Santoro A, Mollica L, et al. Long-term safety and efficacy of the PI3K inhibitor copanlisib in patients with relapsed or refractory indolent lymphoma: 2-year follow-up of the CHRONOS-1 study. $\mathrm{Am}$ J Hematol. 2020;95(4):ajh.25711. doi:10.1002/ajh.25711

34. Nowakowski GS, Gorbatchevsky I, Hiemeyer F, Cupit L, Childs BH. Abstract CT212: CHRONOS-2: a randomized, double-blind phase III study of phosphatidylinositol-3 kinase alpha/delta inhibitor copanlisib versus placebo in patients with rituximab-refractory indolent nonHodgkin's lymphoma (iNHL). Cancer Res. 2015;CT212-CT212.

35. Cheson BD, O'brien S, Ewer MS, et al. Optimal management of adverse events from copanlisib in the treatment of patients with non-hodgkin lymphomas. Clin Lymphoma Myeloma Leuk. 2019;19 (3):135-176. doi:10.1016/j.clml.2018.11.021

36. Hanker AB, Kaklamani V, Arteaga CL. Challenges for the clinical development of PI3K inhibitors: strategies to improve their impact in solid tumors. Cancer Discov. 2019;9(4):482-491. doi:10.1158/21598290.CD-18-1175

37. Zinzani PL, Santoro A, Mollica L, et al. Copanlisib, a PI3K inhibitor, demonstrates a favorable long-term safety profile in a pooled analysis of patients with hematologic malignancies. Blood. 2019;134 (Supplement_1):4009. doi:10.1182/blood-2019-131779

38. Morschhauser F, Machiels JP, Salles G, et al. On-target pharmacodynamic activity of the PI3K inhibitor copanlisib in paired biopsies from patients with malignant lymphoma and advanced solid tumors. Mol Cancer Ther. 2020;19(2):468-478. doi:10.1158/1535-7163.MCT-19-0466

39. Zinzani PL, Santoro A, Mollica L, et al. Outcomes for patients with pre-existing diabetes or hypertension treated with copanlisib from the CHRONOS-1 study in patients with relapsed or refractory indolent B-cell lymphoma. Blood. 2018;132(Supplement1):1613. doi:10.1182/ blood-2018-99-117063

40. Hopkins BD, Pauli C, Xing D, et al. Suppression of insulin feedback enhances the efficacy of PI3K inhibitors. Nature. 2018;560 (7719):499-503. doi:10.1038/s41586-018-0343-4

41. Busaidy NL, Farooki A, Dowlati A, et al. Management of metabolic effects associated with anticancer agents targeting the PI3K-AktmTOR pathway. J Clin Oncol. 2012;30(23):2919-2928. doi:10.12 00/JCO.2011.39.7356

42. Casulo C, Byrtek M, Dawson KL, et al. Early relapse of follicular lymphoma after rituximab plus cyclophosphamide, doxorubicin, vincristine, and prednisone defines patients at high risk for death: an analysis from the national lymphocare study. J Clin Oncol. 2015;33 (23):2516-2522. doi:10.1200/JCO.2014.59.7534

43. Lansigan F, Barak I, Pitcher B, et al. The prognostic significance of PFS24 in follicular lymphoma following firstline immunotherapy: a combined analysis of 3 CALGB trials. Cancer Med. 2019;8 (1):165-173. doi:10.1002/cam4.1918

44. Gopal AK, Kahl BS, Flowers C, et al. Activity of idelalisib in high-risk follicular lymphoma with early relapse following front line immunochemotherapy. Blood. 2015;126(23):2744. doi:10.1182/ blood.V126.23.2744.2744

45. Dreyling M, Santoro A, Leppä S, et al. Efficacy and safety in high-risk relapsed or refractory indolent follicular lymphoma patients treated with copanlisib. Hematol Oncol. 2019;37:387-389. doi:10.10 02/hon.57_2631

46. Cheah CY, Fowler NH. Idelalisib in the management of lymphoma. Blood. 2016;128(3):331-336. doi:10.1182/blood-2016-02-702761

47. Iyengar S, Clear A, Bödör C, et al. P110 $\alpha$-mediated constitutive PI3K signaling limits the efficacy of p110 -selective inhibition in mantle cell lymphoma, particularly with multiple relapse. Blood. 2013;121 (12):2274-2284. doi:10.1182/blood-2012-10-460832
48. Sorensen R, Meadows S, Yahiaoui A, et al. Investigation of the mechanism of idelalisib resistance in the follicular lymphoma WSU-Fsccl cell line. Blood. 2015;126(23):2482. doi:10.1182/blood.V126.23.2482.2482

49. Appukkuttan S, Duchesneau E, Zichlin ML, et al. A budget impact analysis of the introduction of copanlisib for treatment of relapsed follicular lymphoma in the United States. J Manag Care Spec Pharm. 2019;25(4):437-446. doi:10.18553/jmcp.2019.18259

50. Solal-Céligny P, Roy P, Colombat P, et al. Follicular lymphoma international prognostic index. Blood. 2004;104(5):1258-1265. doi:10.1182/blood-2003-12-4434

51. Federico M, Bellei M, Marcheselli L, et al. Follicular lymphoma international prognostic index 2: a new prognostic index for follicular lymphoma developed by the international follicular lymphoma prognostic factor project. J Clin Oncol. 2009;27(27):4555-4562. doi:10. 1200/JCO.2008.21.3991

52. Vindi J, Kridel R, Staiger AM, et al. A clinicogenetic risk model (m7-FLIPI) prospectively identifies one-half of patients with early disease progression of follicular lymphoma after first-line immunochemotherapy. Blood. 2015;126(23):333. doi:10.1182/blood. V126.23.333.333

53. Huet S, Tesson B, Jais JP, et al. A gene-expression profiling score for prediction of outcome in patients with follicular lymphoma: a retrospective training and validation analysis in three international cohorts. Lancet Oncol. 2018;19(4):549-561. doi:10.1016/S14702045(18)30102-5

54. Lockmer S, Ren W, Brodtkorb M, et al. M7-FLIPI is not prognostic in follicular lymphoma patients with first-line rituximab chemo-free therapy. Br J Haematol. 2020;188(2):259-267. doi:10.1111/bjh.16159

55. Nastoupil LJ, Flowers CR, Leonard JP. Sequencing of therapies in relapsed follicular lymphoma. Hematol. 2018;2018(1):189-193.

56. Hirayama AV, Gauthier J, Hay KA, et al. High rate of durable complete remission in follicular lymphoma after CD19 CAR-T cell immunotherapy. Blood. 2019;134(7):636-640. doi:10.1182/blood.2019000905

57. Modi P, Balakrishnan K, Yang Q, Wierda WG, Keating MJ, Gandhi V. Idelalisib and bendamustine combination is synergistic and increases DNA damage response in chronic lymphocytic leukemia cells. Oncotarget. 2017;8(10):16259-16274. doi:10.18632/ oncotarget. 15180

58. Lesokhin AM, Ansell SM, Armand P, et al. Nivolumab in patients with relapsed or refractory hematologic malignancy: preliminary results of a phase ib study. J Clin Oncol. 2016;34(23):2698-2704. doi:10.1200/JCO.2015.65.9789

59. Ali K, Soond DR, Piñeiro R, et al. Inactivation of PI(3)K p110 breaks regulatory T-cell-mediated immune tolerance to cancer. Nature. 2014;510(7505):407-411. doi:10.1038/nature13444

60. Pachter JA, Weaver DT. The dual PI3K- $\delta, \gamma$ inhibitor duvelisib stimulates anti-tumor immunity and enhances efficacy of immune checkpoint and co-stimulatory antibodies in a B cell lymphoma model. Blood. 2017;130(Supplement1):1541.

61. Coyne GO, Yap TA, Moore N, et al. Abstract B105: phase IB combination study of copanlisib and nivolumab in advanced solid tumors and lymphomas. Mol Cancer Ther. 2019;B105-B105.

62. Smith SM, Pitcher BN, Jung SH, et al. Safety and tolerability of idelalisib, lenalidomide, and rituximab in relapsed and refractory lymphoma: the Alliance for clinical trials in oncology A051201 and A051202 phase 1 trials. Lancet Haematol. 2017;4(4):e176-82. doi:10.1016/S2352-3026(17)30028-5

63. Zelenetz AD, Barrientos JC, Brown JR, et al. Idelalisib or placebo in combination with bendamustine and rituximab in patients with relapsed or refractory chronic lymphocytic leukaemia: interim results from a phase 3, randomised, double-blind, placebo-controlled trial. Lancet Oncol. 2017;18(3):297-311.

64. Barr PM, Saylors GB, Spurgeon SE, et al. Phase 2 study of idelalisib and entospletinib: pneumonitis limits combination therapy in relapsed refractory CLL and NHL. Blood. 2016;127(20):2411-2415. doi:10.1182/blood-2015-12-683516 
65. Choudhary GS, Al-Harbi S, Mazumder S, et al. MCL-1 and BCL-xLdependent resistance to the BCL-2 inhibitor ABT-199 can be overcome by preventing PI3K/AKT/mTOR activation in lymphoid malignancies. Cell Death Dis. 2015;6(1):e1593. doi:10.1038/cddis.2014.525

66. Tarantelli C, Lange M, Gaudio E, et al. Copanlisib synergizes with conventional and targeted agents including venetoclax in B- And T-cell lymphoma models. Blood Adv. 2020;4(5):819-829. doi:10.1182/ bloodadvances.2019000844

67. Burris HA, Flinn IW, Patel MR, et al. Umbralisib, a novel PI3K $\delta$ and casein kinase- $1 \varepsilon$ inhibitor, in relapsed or refractory chronic lymphocytic leukaemia and lymphoma: an open-label, phase 1, doseescalation, first-in-human study. Lancet Oncol. 2018;19(4):486-496. doi:10.1016/S1470-2045(18)30082-2

68. Davids M, Flinn I, Mato A. Long term integrated safety analysis of umbralisib (TGR-1202), a PI3K-delta/CK1-epsilon inhibitor with a differentiated safety profile, in patients with relapsed/refractory lymphoid malignancies. 2018 cited October 1, 2020]. Available from: https://library.ehaweb.org/eha/2018/stockholm/214906/mat thew.s.davids.md.mmsc.long.term.integrated.safety.analysis.of.umbra lisib.html?f=listing\%3D0\%2Abrowseby\%3D8\%2Asortby \%3D1\% 2Asearch\%3Dunity.
69. Zelenetz AD, Reddy N, Jagadeesh $\mathrm{D}$, et al. Tolerability and durable response of the $\mathrm{PI} 3 \mathrm{~K} \delta$ inhibitor ME-401 administered on an intermittent schedule in relapsed/refractory $(\mathrm{R} / \mathrm{R})$ follicular lymphoma (FL) and other B-cell malignancies. J Clin Oncol. 2020;38 (15_suppl):8016. doi:10.1200/JCO.2020.38.15_suppl.8016

70. Zelenetz AD, Jagadeesh D, Reddy NM, et al. Results of the PI3K $\delta$ inhibitor ME-401 alone or with rituximab in relapsed/refractory $(\mathrm{R} /$ R) follicular lymphoma (FL). J Clin Oncol. 2019;37(15_suppl):7512. doi:10.1200/JCO.2019.37.15_suppl.7512

\section{Publish your work in this journal}

Cancer Management and Research is an international, peer-reviewed open access journal focusing on cancer research and the optimal use of preventative and integrated treatment interventions to achieve improved outcomes, enhanced survival and quality of life for the cancer patient.
The manuscript management system is completely online and includes a very quick and fair peer-review system, which is all easy to use. Visit http://www.dovepress.com/testimonials.php to read real quotes from published authors. 